\title{
Contato Improvisação como uma Arte de viver [parte 2]
}

\section{Contact Improvisation as an Art of living [part 2]}

Jörg Schmid ${ }^{1}$

Tradução: Bruno Garrote M. ${ }^{2}$ 


\section{Resumo}

A presente tradução é a continuação de uma tradução já publicada na revista Urdimento, v.1, n.28, p. 302-322, Julho 2017, relativa a uma parte do doutorado Contato Improvisação como Arte de viver, de Jörg Schmid da Universidade Philipps de Marburgo. Essa "[parte 2]" foca nos desenvolvimentos e diferentes formas de manifestação do Contato Improvisação $(\mathrm{Cl})$ após a primeira geração de dançarinos, trazendo a influência de outras práticas corporais, bem como o subsequente processo de profissionalização. Começaram, portanto, a surgir questões relativas a: criação de uma comunidade internacional com fóruns abertos; organização de festivais e encontros internacionais; desenvolvimento de plataformas onlines que conseguissem agregar a comunidade sem criar estruturas de poder muito centralizadoras e verticais; estruturação de laboratórios e de jams; discussões de temas recorrentes como os riscos da sexualização, a vivência do fluxo [Flow-Erleben], a atenção plena [Achtsamkeit] etc. Essa tradução pretende continuar contribuindo para o cenário da dança e dos estudos performáticos, mostrando a importância do $\mathrm{Cl}$ como uma crescente e mundialmente disseminada forma de dança contemporânea e pesquisa de movimento corporal, ainda pouco estudada no Brasil.

Palavras-chave: Contato improvisação; dança; performance; história

\section{Abstract}

This translation is the continuation of a translation already published in the periodical Urdimento, v.1, n.28, p. 302-322, July 2017, referring to a part of the doctorate Contact Improvisation as an Art of living of Jörg Schmid from the University Philipps Marburg. This "[part 2]" focuses on the developments and different manifestations forms of Contact Improvisation (Cl) after the first generation of dancers, bringing the influence of other bodily practices as well as the subsequent professionalisation process. It began, therefore, to rise questions relating: creation of an international community with open forums; organization of international festivals and gatherings; development of online platforms that manage to assemble the community without creating too centralized and vertical power structures; arrangement of labs and jams; discussions of recurring teams such as the risks of sexualisation, experience of flow [Flow-Erleben], mindfulness [Achtsamkeit] etc. This translation intends to keep contributing to the scene of dance and of performance studies, showing the importance of $\mathrm{Cl}$ as a growing and worldly disseminated form of contemporary dance and bodily movement research, yet scarcely studied in Br azil.

Keywords: Contact improvisation; dance; performance; history 


\section{NOTA DO TRADUTOR}

Essa é a [parte 2] desse projeto de tradução da tese de doutorado de Jörg Schmid pela Faculdade de Educação da Universidade Philipps de Marburgo, 2011; relativa às páginas 75 a 89 do texto original. A [parte 1] foi publicada na revista Urdimento, v.1, n.28, p. 302-322, Julho 2017. E a tese completa em alemão pode ser encontrada no seguinte link disponível gratuitamente pelo autor (em seu site pessoal) e pela universidade: $h$ ttp://joerg-lemmer-schmid.de/index.php?id=6 - Acesso em: 19 dez. 2016.

Os [colchetes] ao longo desta tradução são manifestações do tradutor no intuito de facilitar a leitura.

Tentou-se manter a disposição das imagens/figuras, tabelas, separação de subtítulos etc. da maneira mais fiel possível ao texto original. Outrossim, não se alterou a numeração original dos títulos e subtítulos - deste modo, esse texto, ou suas imagens/figuras, não se inicia com o número "1", uma vez que se trata de uma seção já no meio da tese.

Apesar desta tese de doutorado ter sido disponibilizada pública e gratuitamente pelo autor e pela universidade, por uma questão de cortesia o tradutor consultou o autor Jörg Schmid sobre esta tradução para o português e ele entusiasmadamente apoiou esse projeto e afirmou não ter problema nenhum a respeito de direitos autorais e de publicação desta tradução.

O formato de citação e referências bibliográficas foram mantidas assim como estavam no original alemão, no intuito de não alterar o estilo do autor e também por ser um formato claro, facilmente compreensível e semelhante à metodologia de pesquisa acadêmica brasileira.

Boa leitura. 


\section{Contato Improvisação como uma Arte de viver [parte 2] ${ }^{3}$}

\subsection{Contato Improvisação \\ [...] \\ O desenvolvimento do Contato Improvisação \\ [...] \\ Novos desenvolvimentos e formas de manifestação}

A partir das oficinas [workshops] e mostras [showings] iniciais, nas quais se transmitiam compreensões dessa forma de dança por meio da introdução de exercícios e situações a serem experienciadas, desenvolveram-se os ainda hoje praticados "laboratórios" [Worklabs] ${ }^{4}$. Semelhantemente aos praticantes de artes marciais, que se encontram nos chamados "dojo" para treinarem livremente, os "laboratórios" são uma reunião de dançarinos, que pesquisam e desenvolvem juntos formas de movimentos (veja: Novack 1990, 174). Novas descobertas são demonstradas e compartiIhadas. "O Contato me lembra do software de computador 'Unix'. Todos que conhecem a linguagem básica pode evoluí-lo. Invenções que funcionam se tornam parte do sistema" (Hassmann 2006)5. O Contato Improvisação evoluiu basicamente, em determinado momento, a partir de si mesmo. "A dança faz o ensino" (Paxton, 1976).

Além desses laboratórios, desenvolveram-se também as chamadas "Jams", onde a diferença entre uma jam e uma oficina ou um laboratório consiste em não existir mais nenhuma instrução ou troca explícita. Dançar é o foco. Assim como músicos, especialmente músicos de jazz que se reúnem para fazer música juntos improvisando, também no Contato se dança junto - "jamisado". "A Jam é a parte central [Herzstück] do Contato Improvisação, lá vive a dança. É como uma cerimônia para a qual os dançarinos se preparam" (Hassmann 2009) ${ }^{6}$. Alguém aluga um estúdio de dança por duas a três horas e convida para dançar. Às vezes há uma pessoa que conduz um aquecimento e novamente aponta alguns importantes acordos e regras de segurança - em seguida é cada um por si. Basicamente uma jam ocorre semelhantemente aos já descritos boogies descalços, porém o foco está no movimento a partir do contato corporal. Pallant (2006) descreve uma possível introdução para a jam assim: "Aqueça seu corpo, entre em um solo de dança, e se mova para uma seção do chão onde encontros com outros dançarinos são prováveis. Respire e deixe a dança acontecer" (Pallant 2006, 28).

As "Jams" foram, devido à grande demanda em meados dos anos 70 nos EUA, estendidas para a duração de um fim de semana. A primeira jam prolongada nos EUA foi a "Jam Breitenbush" em Oregon. Depois de um curto período de tempo, a demanda era tão grande que mais e maiores jams foram oferecidas, como, p. ex., a "Jam Harbin Hot Springs" na Califórnia ou a "Jam East Coast" na Virgínia Ocidental. Enquanto isso, havia um número muito grande de jams realizadas anualmente (Pallent 2006, 15). Dentre as maiores jams e festivais dos EUA estão: "the West Coast Contact Improvisation Festival (WCCIF), the Seattle Festival of Dance Improvisation,

\footnotetext{
${ }^{3}$ A "parte 1" desta tradução foi publicada na Urdimento n. 28, v. 1, de 2017. Ela pode ser encontrada no: DOi = http://dx.doi.org/10.5965/1414573101282017302.

4 "Lab" é a abreviatura coloquial para laboratório.

${ }^{5}$ Script inédito sobre Contato Improvisação.

${ }^{6}$ Entrevista em Berlim, 2009.
} 
GLACIER (Great Lakes Area Contact Improvisation Enthusiasts Retreat), Boston Cl Festival, Western Mass Moving Arts Festival at Earthdance e Ground Research Connecticut" (Horrigan 2010)7. Também na Europa, e eventualmente, também na Alemanha, o Contato se espalhou rapidamente no início dos anos 80 pelas recorrentes temporadas de ensino e apresentações de Steve Paxton, Mary Fulkerson, Nancy Stark Smith, Nina Martin, Bob Rease e outros. Christine Vilardo, Reinhard Krätzig, Wolfgang Graf, Prof. Heitkamp, Prof. Koegel, Ka Rustler, Lilo Stahl ${ }^{8}$ e Bernd Ka ${ }^{9}$ são, segundo minhas pesquisas, os primeiros dançarinos alemães que aprenderam Contato e, em certa medida sem saberem uns sobre os outros, ensinaram em diferentes partes da Alemanha (Berlim, Friburgo, Dusseldorf, Stuttgart) ao mesmo tempo (Heitkamp 2010, Koegel 2010, Rustler 2009). Keriac, uma professora também originalmente da Nova Dança de São Francisco, é uma das pioneiras que espalhou o Contato pela Alemanha. "Ela ensinou de 1984 à 2004 na formação em tempo integral 'Dancing together' ["dançando junto"] em Stuttgart e em São Francisco (EUA); e apoiou, deste modo, um grande número de pessoas em seu caminho enquanto artista ao longo dos anos", informa Barbara Stahlberger, uma dos três organizadores principais do Festival de Contato de Friburgo (Stahlberger 2010) ${ }^{10}$.

Enquanto isso, existem em cada cidade importante da Alemanha Jams regulares. O jornal Contato-Trimestral [Contact-Quarterly] possui um folhetim, no qual são anunciadas oficinas de Contato, jams e festivais de 40 países. "Festival" significa no contexto do Contato Improvisação uma mistura de oficinas, fases de exploração auto-organizadas (laboratórios) e jams. Em muitas propostas é possível observar, como descrito acima, a influência mútua entre outras formas de movimento e escolas de pensamento.

$\mathrm{Na}$ Tabela 2.1 alguns títulos das oficinas do Festival de Contato de Friburgo mostram exemplarmente como o Contato Improvisação $(\mathrm{Cl})$ foi combinado explicitamente com outros métodos ou abordagens:

Tabela 2.1:

Temas das Oficinas

$\begin{array}{lll}\begin{array}{l}\text { Ano } \\ 2000\end{array} & \begin{array}{l}\text { Título } \\ \text { Cl \& Estrutura esquelética } \\ \text { (Anatomia) }\end{array} & \begin{array}{l}\text { Instrutores } \\ \text { Peter Arni }\end{array} \\ 2001 & \text { Cl e Capoeira } & \text { Muriel Mollet } \\ 2002 & \text { Cl e Yoga } & \text { Judith Sacks } \\ 2003 & \text { Filosofia em Movimento } & \text { Jaap Klevering } \\ 2004 & \text { Cl e Feldenkrais@ } & \text { Thomas Kampe } \\ 2005 & \text { Cl e Aéreos (Arte trapezista) } & \text { Pipaluk } \\ & & \text { Supernova } \\ 2006 & \text { Cl e Tango } & \text { Javier Cura } \\ 2006 & \text { Cl e Técnica Alexander@ } & \text { Lucia Walker } \\ 2007 & \text { Cl e Mindfulness } & \text { Dieter Rehberg } \\ 2008 & \text { Cl e Movimento ocular } & \text { Nien Mari Chatz } \\ 2009 & \text { Cl e Fluxo } & \text { Lemmer Schmid } \\ 2010 & \text { Cl e BMC@ } & \text { Ka Rustler }\end{array}$

(Fonte: URL:http://www.contactfestival.de/archiv/past.htm. Acessado: 03.10.2010)

\footnotetext{
${ }^{7}$ Contato por email, 2010.

${ }^{8}$ Contato por e-mail, Stahl (2010): "à nossa comunidade de Cl no final dos anos setenta aqui em Friburgo também pertencem Ulrike Digel e Sasha Waltz.

${ }^{9}$ Contato por email Ka (2010): "Para nós, principalmente, Laurie Booth foi um professor importante. Ele veio em 1979 (ainda como estudante em Dartington) para oficinas em Estrasburgo e Friburgo, e nos tornou íntimos não somente com o Contato, mas principalmente com o cenário da dança pós-moderna/nova dança dos EUA e Inglaterra, das quais os representantes mais importantes foram convidados por nós para Friburgo já no começo dos anos 1980 (Nancy Stark Smith, Kirstie Simson, Steve Paxton e muitos outros).

${ }^{10}$ Contato por e-mail, 2010.
} 
A seguir, a mistura de Tango e Contato (Contango) é descrita de forma impressionante pelo argentino Javier Cura (Cura 2010¹1):

$\mathrm{Na}$ dança Contato Impro, forças circulares, desviantes ou "tangenciantes" mudam o ponto de contato e o eixo de orientação, permitindo a continuidade de um fluxo de energia e o fator surpresa, nos quais os parceiros de dança "caem em situações" despreparados.

No Tango, ao contrário, uma clara intenção direcionada ao nosso parceiro organiza os giros [rolls] imaginários dos parceiros de dança. Este, por sua vez, organiza o corpo em torno de um eixo vertical, criando um tipo diferente de espaço. Ao mesmo tempo, o valor dado à música, com seus distintos ritmos, melodias e atmosferas, reforça a criação de um mundo simbólico compartilhado.

De um modo material e simbólico, eu espero combinar a circularidade do Contato com a incisividade do Tango. Seguindo a continuidade de um fluxo, os parceiros "caem em diferentes situações". E, ao mesmo tempo, a clara intenção do jogo de papéis [role playing] os permite dar um valor expressivo para cada situação e encarar o inesperado com uma estrutura se organizando.

Quanto mais claro for para ambos os parceiros de dança que eles estão jogando um jogo de constante mudança de situações e papéis, tanto mais clara a sua expressão será.

No final, eu acredito que essa dança teatral física pode permitir a expressão das criações dinâmicas e múltiplas de nosso próprio ser.

Javier Cura 12.10.2010

É cada vez mais comum também em festivais as misturas entre outras formas artísticas fora da dança. O festival de improvisação de Göttinger ${ }^{12}$, ocorrendo anualmente desde 2001, focaliza, já na primeira linha, no aspecto da improvisação. Além das aulas puramente de Contato, os participantes podem se inscrever em oficinas de âmbitos artísticos como pintura, teatro ou música. O objetivo é encontrar uma expressão artística nos mais diferentes planos possíveis, nos chamados "espaços abertos" [Openspaces], e se comunicar uns com os outros. "O Espaço Aberto é um espaço para o encontro de todos os canais de comunicação disponíveis no momento", explica Ingo Rosenkranz, um dos quatro organizadores principais (Rosenkranz 2007). ${ }^{13}$

"O Contato se desdobrou em uma multidão de direções - em outras áreas além da dança, incluindo meditação, jogo, terapia, recreação, exercício, esporte e necessidades especiais" (Pallant 2006, 16). Quanto mais o Contato se misturar com outras formas de movimentos e de arte, mais difícil se torna também a pergunta sobre o núcleo essencial do Contato Improvisação. A partir de qual grau de afastamento ainda se pode falar em Contato Improvisação? Essas e tantas outras perguntas são discutidas nas Conferências anuais ECITE (European Contact Improvisation Teachers Exchange ${ }^{14}$. Este é um intercâmbio de seis dias entre professores de contato europeus.

$\mathrm{Na}$ seção seguinte, entrar-se-á nessas conferências. Eles formam, ao lado das plataformas na internet e do jornal Contato-trimestral, uma base essencial para a profissionalização do Contato Improvisação.

\footnotetext{
${ }^{11}$ Contato por e-mail, 2010

${ }^{12}$ www.Oster-improvfestival.org

${ }^{13}$ Entrevista em Göttingen, 2007. Ingo.

${ }^{14}$ [Em português seria IEPCI (Intercâmbio Europeu de Professores de Contato Improvisação)].
} 


\section{Profissionalização}

Professores como Nancy Stark Smith, Martin Keogh, Ray Chung ou Jörg Hassmann, que ensinam explicitamente e exclusivamente Contato, são atualmente, na verdade, a exceção. No entanto, existe mundialmente uma grande rede de professores que sempre se reúnem para trocar experiências sobre os desenvolvimentos e a didática do Contato Improvisação.

A primeira conferência de Contato ocorreu no ano de 1980 pela iniciativa de Elizabeth Zimmer no Canadá. Mais de 300 dançarinos vieram dos EUA, Canadá e Europa e participaram de discussões, palestras e oficinas durante 5 dias. A principal palestra desta época foi a do Steve Paxton (cf. Novack 1990, 90). No verão de 1983, Paxton organizou, em vista do décimo aniversário de existência, a segunda conferência com o nome "Contato na décima e segunda" [Contatct at 10th and 2nd]. Em performances e em discussões parcialmente públicas conversou-se sobre as mudanças, mas também sobre a continuidade do Contato Improvisação (cf. Novack 1990, 101). Depois de alguns grandes e não-oficiais encontros de intercâmbio, ocorreu a primeira conferência de Contato europeia pela iniciativa de Stark Smith no ano 1985 em Amsterdã. Sob o nome ECITE esses encontros ocorrem, desde então, anualmente e sempre em um país europeu diferente. "ECITE é a reunião de cerca de 70 pessoas, que ensinam e se preocupam com Contato, e que desenvolvem essa forma em sua prática diária de trabalho, para compartilharem e aprenderem entre si. Há uma necessidade da dança de ser ensinada, há uma necessidade da improvisação continuar infiltrando-se na estrutura acadêmica do ensino da dança, da história da dança e da teoria. Enquanto existir uma demanda para a pesquisa da dança e pedagogias de Contato Improvisação na Europa, o ECITE continuará ocorrendo" (Verkasalo 2010)..$^{15}$

Walter Weiler, um professor de Contato originário da Suíça e terapeuta familiar, frequentou, desde a primeira conferência em 1985, praticamente todas as conferências. Em uma tabela complementar minha, mas ainda incompleta, ele coletou em 2006 todos os lugares, temas e organizadores das conferências. "A conferência anual foi fundamental para a fase pioneira do $\mathrm{Cl}$ na Europa. Tratou-se de sair do isolamento e desenvolver uma compreensão conjunta, europeia e autônoma dessa forma de dança e do ensino. Também foi um ato de associação, de coalização. Além disso, a dança entre colegas avançados foi uma experiência importante, o que na época era raro. Eu acho que a posterior disseminação e desenvolvimento com todos os festivais e jams de finais de semana não teriam ocorrido com a mesma intensidade sem o ECITE (Weiler 2010). ${ }^{16}$

A cada ano era decidido ao final da conferência onde o próximo encontro ocorreria e quem iria organizá-lo. Os organizadores assumiam, então, a responsabilidade pela estrutura básica, como as inscrições dos participantes, aluguel das salas, organização dos alojamentos e alimentação etc. O arranjo dos conteúdos das conferências era, porém, em grande parte determinada pelos professores

\footnotetext{
${ }^{15}$ Contato por e-mail, 2010. Ronja Verkasalo era uma membra do time de organização da ECITE 2010 na Finlândia.

${ }^{16}$ Contato por e-mail, 2010
} 
presentes no local. "A nossa escolha foi dar a responsabilidade para os participantes fazerem, eles mesmos, o tipo de ECITE que eles precisavam, e receberem o que eles vieram buscar" (Verkasalo 2010). ${ }^{17}$ Alguém tem um tema específico, p. ex., "Como ensinar iniciantes" e propõe, então, um laboratório [Worklab]. Jörg Hassmann descreve o percurso típico de um Laboratório da seguinte forma: “Um laboratório é algo como um processo de aprendizagem auto-direcionado para um grupo. O formato dos laboratórios é [algo] bastante avançado." (Hassmann 2009). ${ }^{18}$

Na Tabela 2.2 é mostrado um possível Guia para laboratórios:

Tabela 2.2: Guia para a formação de laboratórios

Fase

1. Áreas de interesse

2. Início concreto

3. Reflexão intermitente [Zwischenreflexion]

4. Reinício concreto

5. Reflexão final

\section{Objetivo/Questionamentos}

Quais sãos as áreas de interesse? Sobre quais temas estamos de acordo?

Como devemos abordar o tema?

Como e quando uma reflexão intermitente pode ser integrada, a fim de se verificar se o laboratório está se desenvolvendo na direção desejada.

Como se deve, agora, retomar o trabalho depois de uma reflexão intermitente?

De que maneira pode ser feita uma reflexão final? Como as descobertas podem ser apresentadas e compreendidas?

[Fonte:] (Hassmann 2009) $1^{9}$

Os laboratórios também podem ser rodas puramente de discussão. $\mathrm{Na}$ Tabela 2.3 alguns possíveis tópicos foram listados. Eles se originaram de um painel de discussão do Festival de Contato de Friburgo de 2009. O público foi convidado a formular, em uma pergunta, o que os move atualmente para o tema "Contato Improvisação".

Tabela 2.3: Possíveis temas de Laboratórios

1. Como e por quê nós ensinamos Contato?

2. Daqui a 37 anos nós ainda dançaremos Contato? (Contato e o corpo envelhecendo)

3. O Contato será, em algum momento, parte do currículo escolar? Como podemos contribuir para isso? Como crianças e adolescentes podem descobrir esta forma de dança? Como seria a influência deles sobre essa forma [de dança]?

\footnotetext{
${ }^{17}$ Contato por e-mail, 2010.

${ }^{18}$ Entrevista em Berlim, 2009.

${ }^{19}$ Comunicação pessoal, Contato por email, 20.9.2010.
} 
4. Quais pessoas sentem-se atraídas pelo Contato e quais repelidas?

5. Que influência tem a situação política de um país no desenvolvimento do cenário do Contato?

6. Como pode o Contato ser usado como uma ferramenta para processos de mudança social? Por que o Contato é pouco disseminado em alguns países (p. ex., Holanda, França) e tão extremamente [disseminado] em outros países como Alemanha?

7. Que influência existe no fato do Contato atualmente se espalhar aparentemente principalmente pelos Festivais? O que é transportado/alterado com isso?

8. Como o Contato influencia nossa vida social? Ele reflete as nossas vidas? A nossa psiquê?

9. Como a consciência corporal e as descobertas das explorações durante a prática podem ser traduzidas para uma linguagem científica-acadêmica?

10. O Contato Improvisação modifica a maneira e o modo como nós pensamos, compreendemos? Ele tem uma influência em nossa consciência, intuição e comportamento?

[Fonte:] (Gravação de áudio do painel de discussão do Festival de Contato de Friburgo de 2009)

Um meio essencial para manter vivo o intercâmbio e contato também entre os encontros de ECITE é a internet ou um fórum virtual ${ }^{20}$. Por exemplo, em 2008 foi longamente discutida a questão sobre se Israel, enquanto país não-europeu, poderia organizar um ECITE. O núcleo dessa discussão muito controversa foi deslocado, ao final, para a questão sobre de que modo e maneira o fórum ECITE pode tomar decisões. Foi criticado que a internet não seria o meio adequado para isso. Argumentou-se que as decisões devem ser tomadas somente pelas pessoas presentes na conferência ECITE. Na minha opinião, a comunidade internacional de Contato $^{21}$ está diante de um dilema insolúvel. Por um lado, há o desejo de uma rede ideal e de um apoio mútuo entre os professores profissionais de Contato. "Profissional" refere-se a professores que integralmente performam [performen] e ensinam Contato, ou àqueles que, ao menos, têm grande parte de sua renda dependendo dele. Por outro lado, existe, em muitos dançarinos de longa data, uma recusa categórica de quaisquer formas de organização e estruturas que possam arrogar uma competência para tomar quaisquer decisões para a comunidade do Contato. Devido à história do desenvolvimento desta forma de dança, a sua autonomia ainda hoje é dogmaticamente defendida.

Em 2009, Dieter Heitkamp, Nancy Stark Smith, Eckard Müller, Norbert Pape e outros, no ECITE da Inglaterra, apresentaram uma enciclopédia virtual de Contato 22 , formada prioritariamente por textos, imagens e filmes sobre Contato. Além disso, esta página deveria incluir também um calendário global e central para todos os eventos de Contato. Por causa da dificuldade em se conferir sites virtuais "privados", que anunciam eventos regionais e também parcialmente supra-

\footnotetext{
${ }^{20}$ URL: http://www.ECITE.org; URL: http://groups.yahoo.com/group/ECITE-forum

${ }^{21}$ Também na cena do Contato alemã a palavra inglesa "comunidade" [community] é utilizada, em invés de "Gemeinschaft" [comunidade].

22 URL: http://www.contactencyclopedia.net
} 
-regionais, esta iniciativa se esforçou para reunir todas as informações. Porém, os iniciadores [dessa ideia] esbarraram, pelos motivos já ditos, na resistência da comunidade do Contato. Novamente, o principal argumento contrário a uma página administrada de forma central foi a necessidade de autonomia e diversidade (Heitkamp 2010) ${ }^{23}$. Por este motivo foi desenvolvido um programa de internet especial, cujo nome do projeto era "round robin", por meio do qual páginas "privadas" poderiam continuar funcionando, porém com a possibilidade de seus conteúdos serem automaticamente intercambiados entre si. Cada página individual possui todas as informações de todas as páginas que participam desta rede de contatos compartilhada. Por meio do acesso a uma página se pode conhecer o local, data e horário de todas as jams. "Um primeiro módulo deste projeto round robin é o 'calendário' (o que acontece e onde?), um outro módulo será o 'arquivo' (que material, filme ou texto... e onde encontrar?), um outro módulo será a 'lista de pessoas $\&$ lugares', que lista pessoas e lugares associados ao Contato ${ }^{24 "}$ (Muller 2010). ${ }^{25}$

Momentaneamente, o Contato Improvisação e a sua disseminação pode ser descrito, no sentido mais amplo [desta expressão], como um ensinamento entre mestre e aprendiz [Meisterlehre]. Isso se dá principalmente porque muitos dos conhecimentos são compreendidos e conservados de modo corporal pré-verbal. De modo que uma grande parte do conhecimento está ligada à própria pessoa, não sendo transmitida por livros ou palestras. Na minha opinião, porém, ocorre atualmente uma constante e crescente cientificação. Existem, portanto, além da já descrita conferência de Contato ECITE, cada vez mais laboratórios sobre o tema "Contato e Pesquisa" ou "Contato e Academia". Eu suspeito que, por causa disso, em um futuro próximo, principalmente os já descritos fóruns virtuais serão ainda mais intensivamente utilizados para, p. ex., também publicar resultados e descobertas de alguns laboratórios. Deste modo, algumas posições seriam discutidas. Avanços no conhecimento seriam documentados, não sendo necessário novamente serem refeitos em cada laboratório. Um passo importante seria o ainda desenvolvimento de uma sistemática, pela qual terminologias poderiam ser organizadas. Ainda é preciso esperar para saber em que medida o projeto round robin será recebido pela comunidade do Contato. Na minha opinião, esta iniciativa é um excelente acordo entre uma autonomia com uma concomitante transparência e uma rede mundial da atual comunidade do Contato. Este seria um importante passo para um desejado profissionalismo.

\section{O risco da sexualização}

No Contato Improvisação uma intimidade pública é cultivada (cf. Novack $1990,164)$. Toda a superfície do corpo pode ser envolvida na dança. Apesar de uma proximidade física normalizada existe uma clara diferença entre uma dança sensorial [sinnlichen Tanz] e um contato sexual [sexuellen Berührung]. Embora o

\footnotetext{
${ }^{23}$ Entrevista em Friburgo, 2010

${ }^{24}$ TInformações mais detalhadas sobre este projeto podem ser encontradas em http://roundrobin.ecite.org

${ }^{25}$ Contato por e-mail, 2010. Eckard Muller é um dos três organizadores principais do Festival de Contato de Friburgo e co-iniciador do projeto round robin.
} 
Contato seja uma cria da geração flower power [força das flores], o "amor livre" não é um dos valores propagados. No entanto, a tematização desta época sobre a cultura do corpo livre e a queda do tabu para se falar sobre a sexualidade foi um propício chão fértil para se estabelecer uma forma de dança como o Contato. "O movimento em direção à liberdade sexual dos anos 60 e 70 levou a uma noção física diferente do próprio corpo em relação a outros corpos. Isso, por sua vez, permitiu o potencial para uma nova maneira de dançar e interagir fisicamente" (Khambatta 2010). ${ }^{26}$

Hassmann manifestou-se sobre o tema Contato e Sexualidade da seguinte maneira: "A energia sexual pode ser uma poderosa fonte de força para a minha dança. Mas eu uso essa energia exclusivamente para o movimento. Trata-se do dançar. Se eu percebo uma dupla em algum lugar da jam e tenho um sentimento de que eu não posso olhar para lá, então isso restringe o meu espaço de movimento e me consome energia" (Hassmann 2009) ${ }^{27}$. Mesmo existindo uma fronteira entre sensorialidade [Sinnlichkeit] e sexualidade [Sexualität], pode-se, no entanto, se chegar a mal-entendidos. Sempre é possível observar dançarinos e dançarinas que abusam do contexto do Contato Improvisação para procurar um parceiro sexual. Steve Paxton sempre enfatizava em seus cursos para não nos perdermos em "jogos emocionais". "O Steve disse: o contato pode evocar muitas emoções. 'As relações pessoais são química, mas o contato é sobre física!' Em uma dança de contato pura, a sua mente está muito ocupada para ter espaço para esses tipos de reflexões; a dança toma toda sua atenção" (Walker 201028, ver também Novack 1990, 168). Sempre são publicados e discutidos artigos sobre o tema Contato e Sexualidade no Contato-Trimestral [Contact-Quarterly] e em outros jornais ou páginas da internet (ver Lori 1994, Frost 1999, Heitkamp 2007). Heitkamp recorda em uma entrevista publicada: "No ECITE em Amsterdã 1986, nós colocamos o tema (Contato e Sexualidade) na pauta e muitos grupos de trabalho ocuparam-se com ele. Isso estava relacionada aos desenvolvimentos em São Francisco, onde existiam grupos para 'cura sexual' [sexual healing] assim como a preocupação com a AIDS e essas coisas. Nós começamos com exercícios para dizer não, onde nós observávamos: 'Eu quero ou não quero isso? [...] Como eu lido com esta energia sexual?" (Heitkamp 2007).

\section{Contato Improvisação, Vivenciar-o-fluxo's e Atenção plena ${ }^{30}$}

$\mathrm{Na}$ prática da dança do Contato vivenciar o fluxo desempenha um papel central. Muitos anúncios de oficinas de Contato utilizam, no título ou na descrição, explicitamente o termo "fluxo". Segundo o entendimento de Jörg Hassmann $(2009)^{31}$, o princípio básico da técnica do ponto de contato em rolamento corresponde a uma qualidade de movimento fluida e contínua. Nita Little (2009)32,

\footnotetext{
${ }^{26}$ Entrevista em Friburgo, 2010.

${ }^{27}$ Entrevista em Berlim, 2009.

${ }^{28}$ Entrevista em Friburgo, 2010.

${ }^{29}$ [Flow-Erleben]

${ }^{30}$ [Achtsamkeit]

${ }^{31}$ Entrevista em Berlim, 2009.

${ }^{32}$ Comunicação pessoal no encontro de professores do Festival de Contato da costa oeste, São Francisco, 2009.
} 
também uma dançarina da primeira geração, descreve, em uma conversa sobre fluxo, um exercício que faz a vivência do fluxo ser claramente experienciável: a tarefa consiste em manter o ponto de contato em rolamento constantemente em movimento em uma velocidade [Tempo] inalteradamente lenta. Aqui, não há pausas. A percepção [Wahrnehmung] para os detalhes do movimento e das reações corporais [Körperfeedbacks] aumenta durante esse exercício. Essa simples atividade focada torna relativamente fácil "desligar a cabeça". O movimento até então "direcionado" passa a ser um inconsciente "deixar acontecer" do fluxo do movimento. Assim, desaparece qualquer distração mental e planos para o momento seguinte.

Vivenciar o fluxo é descrito como um constante dizer-"sim" para o que acontece no momento. Acerca disso, Martin Keogh (2008) ${ }^{33}$ diz que os dançarinos com uma crescente experiência de Contato aceitam a grande aventura de abandonar as suas "posições seguras" (ver Figura 2.8).

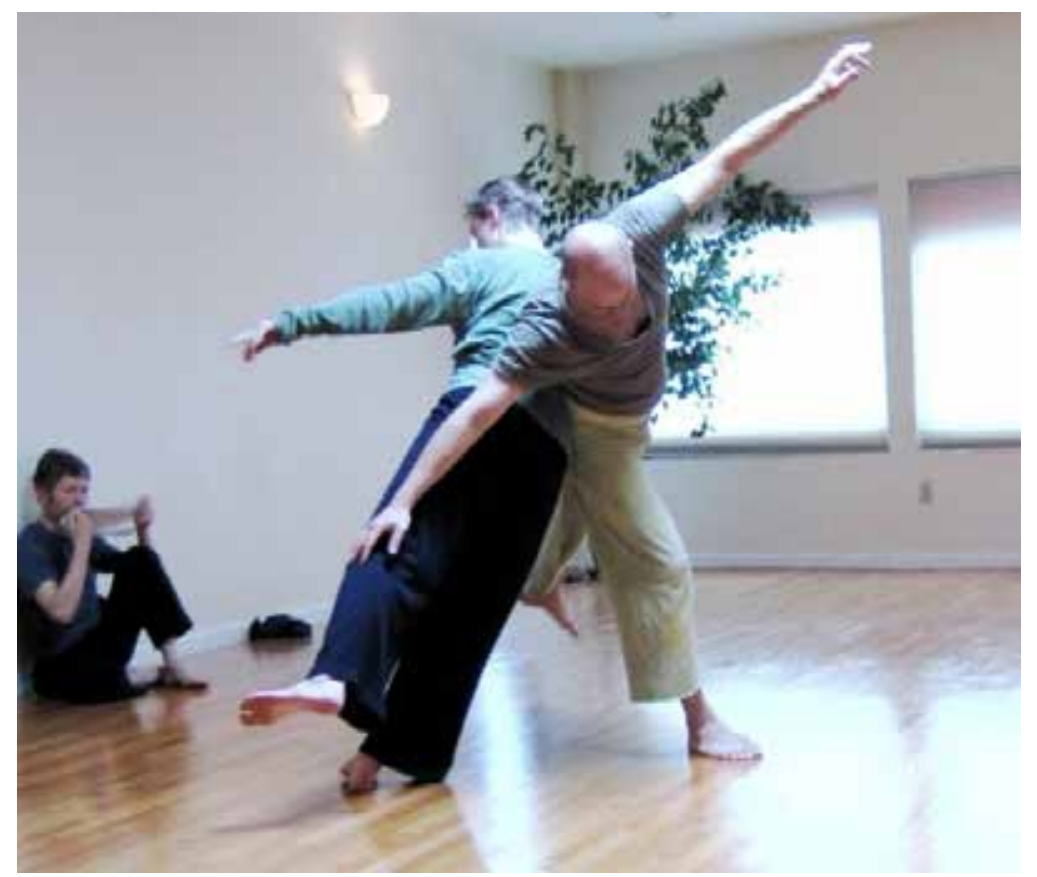

Figura 2.8: Martin Keogh "fora de equilibrio" [off balance]

(Foto: Martin Keogh)

Através de um apoio mútuo surge um centro comum. Os movimentos do parceiro de dança influenciam, deste modo, imediatamente também os próprios. Isto requer uma prontidão para dizer "sim" e para se entregar a um fluxo de movimentos ainda não-imaginado e, principalmente, não-planejado. Em uma queda contínua treina-se a confiança de que o "corpo comum" encontrará um caminho, adaptado pelos desafios do momento, para reagir sem que, para isso, seja necessária uma reflexão consciente. 
No livro de introdução ao Contato Improvisação de Kaltenbrunner (2009), eu tentei, no capítulo "Contato e Fluxo", transpor a teoria do fluxo de Csikszentmihalyi para o Contato Improvisação. A partir disso, possibilidades concretas de ação poderiam ser derivadas, por meio das quais a probabilidade do fluxo na dança pode ser aumentada (ver Schmid 2009a, 215). Em uma série de estudos de campo, dançarinos foram convidados a descrever o seu caminho para o estado-de-fluxo [Flow-Zustand]. Assim, mostrou-se que existem técnicas e portas completamente diferentes. Mesmo quando a vivência do fluxo ocorre por acaso, como dormir, algumas preparações, no entanto, podem ser realizadas para se aprofundar no fluxo. Assim como à noite a cama/leito [Bett] pode ser acomodada e, p. ex., a luz diminuída, o "leito-do-fluxo" [Flussbett ${ }^{34}$ ] também pode ser preparado. Por qual porta uma entrada para o fluxo será mais rapidamente encontrada depende principalmente de preferências individuais e das atuais condições de sensibilidade [Benfindlichkeiten]. Para uma pessoa é uma música, para outras são exercícios respiratórios ou correr rapidamente pela sala. Uma fórmula geral, que sempre funciona para todas as pessoas, não existe. Nem toda dança leva ao vivenciar do fluxo. Todas as preparações e técnicas dominadas não garantem isso. Ao contrário, vivenciar um fluxo profundo é algo excepcional. Em uma dissertação recém- publicada sobre dança e os chamados "bloqueios" [Blockaden], a bailarina grega Vanio Papadelli diz que o objetivo principal na dança não pode nem deve ser um estado permanente de vivência do fluxo. Em sua percepção, resistências internas e momentos de estranhamento possuem frequentemente também um valor não-reconhecido dentro de um processo criativo. "Não há um corpo e mente idealmente 'des-bloqueados'; pelo contrário, bloqueios reforçam a identidade criativa de alguém e fornecem um imenso campo de descobertas" (Papadelli 2009) ${ }^{35}$.

Como ainda será mostrado, o Contato Improvisação promove não somente a compreensão teórica e prática da vivência do fluxo, mas, ao mesmo tempo, ensina também uma disposição interna para uma atenção plena [Achtsamkeit]. Os momentos de pausa, o reconhecimento e também a aceitação de bloqueios do fluxo de movimento são componentes imanentes ao Contato. A cena do Contato oferece, na minha opinião, espaços para experiências, nos quais a plena consciência-atenção [Aufmerksamkeit] pode ser direcionada para a integralidade das sensações corporais. Assim, existem frequentemente, p. ex., no começo de oficinas e jams fases de relaxamento e exercícios de sensibilização corporal. A já descrita "Pequena Dança" é um exercício clássico de Contato, que explicitamente ensina a capacidade de percepção (corporal) consciente sem uma resposta imediata. Os dançarinos observam na "Pequena Dança" as reações involuntárias do corpo que garantem o equilíbrio na posição em pé.

Nos aquecimentos conduzidos, os dançarinos são estimulados a "chegarem por inteiro" e a se tornarem conscientes [aufmerksam] da própria disposição e da atmosfera do espaço. Uma instrução muito comum consiste em percorrer conscientemente

\footnotetext{
${ }^{34}$ [Uso de ambiguidades propositais no original. Bett é cama/leito. Em seguida ele traz a expressão Flussbett. Fluss pode ser entendido como rio ou como fluxo, ou seja, Flussbett pode ser traduzido/lido como leito do rio ou como leito do fluxo.]

${ }^{35}$ Fala em um laboratório sobre o tema "Contato e Fluxo", Festival de Contato de Friburgo, 2009.
} 
o espaço e em observar cuidadosamente tudo o que pode ser observado neste momento. Quantos ruídos são percebidos? É possível sentir o que ocorre atrás das costas (Backspace)? Quantos dançarinos vestem um pedaço de roupa vermelha? Como está a sua própria respiração? Através destes tipos de impulsos não somente a atenção plena é aguçada para as sensações e condições próprias de sensibilidade, mas também a percepção consciente do ambiente e das pessoas ali presentes é estimulada.

Quando dois contateiros avançados dançam entre si, podem ser observadas, em primeiro lugar, sequências de movimento muito fluidas, que sugerem uma vivência de fluxo. Em segundo lugar, este fluxo de movimento é sempre interrompido por pequenas pausas [Pausen] e suspensões [Stopps]. Estes são os momentos nos quais uma direção de movimento não pôde ser continuada em vista de limitações anatômicas ou, p. ex., de um impulso (Momentum) insuficiente. Nessas pausas observáveis de fora, os dançarinos ficam sentindo, sem estabelecer imediatamente novos impulsos. Eles estão abertos e atentos para aonde o "ponto de contato em rolamento" quer continuar se movendo. É uma breve pausa para recuperar o fôlego antes de começar a próxima sequência de movimentos. Este processo pendular entre uma percepção atenta e movimentos fluidos é, portanto, repetidamente observável em dançarinos avançados, pois iniciantes muitas vezes tendem a sempre criar novos impulsos sem escutar atentamente o que já está lá ou o que quer surgir. Esta é uma atitude de atenção plena [Achtsamkeit], uma presença não intencional no presente. Torna-se, então, claro como o fenômeno do fluxo e a atenção plena estão estreitamente entrelaçados com o Contato Improvisação.

\section{Resumo e Referências para o questionário}

A partir da performance do Projeto "Magnesium" e das primeiras apresentações na Galeria John Webber em 1972, desenvolveu-se [...] uma forma de dança espalhada pelo mundo todo, que está entre "os estilos mais importantes do pós-moderno" (Kirschner 2000, 65). "A partir do trabalho de palco inicial e da exploração de novos princípios de movimento, o Contato Improvisação desenvolveu a 'Jam' como sua parte central [Herzstück]. Enquanto isso, o Contato se expandiu de uma arte performática para uma dança popular como, p. ex., o Tango. O que a Milonga é para a dança em dupla na Argentina, a Jam é para o Contato" (Hassmann 2009). 36 "O Contato Improvisação desempenha hoje um indispensável papel na formação do(a) dançarino(a) profissional. [...] E, em um espectro maior, o Contato Improvisação é encontrado no campo da pedagogia na educação de adultos." (Kirschner 2004, 130). Devido a sua história de desenvolvimento, também são transportados ainda hoje para dentro do cenário do Contato uma série de valores humanitários, que possuem uma influência sobre seus membros ainda a ser melhor pesquisada. Assim, p. ex., o valor representativo de evitar hierarquias e estruturas de poder, particularmente forte dentro da comunidade do Contato, está fortemente em conflito com a necessidade de alguns professores de Contato de fundar uma plataforma comum, que possibilitaria o aces-

${ }^{36}$ Entrevista em Berlim, 2009. 
so [Überschaubarkeit] não somente a eventos [Angebote] atuais, mas principalmente também a quaisquer informações arquivadas (textos, filmes, imagens etc.). Pode-se dizer que o Contato Improvisação não se deixa limitar somente pela dança em si. Onde quer que o Contato seja dançado, cria-se também sempre um cenário, que cresce juntamente com um movimento mundial com suas normas e valores próprios. A exata estrutura deste cenário e a sua influência sobre a qualidade de vida subjetiva de seus membros ainda é, todavia, uma pesquisa a ser feita com maior precisão.

Uma reflexão fenomenológica do Contato Improvisação permite assumir que a vivência-do-fluxo e também a disposição interna para uma atenção plena formam um componente imanente à dança. Um autêntico - e portanto não executado para um observador - dueto de Contato ocorre ondulantemente com fluídas pausas e intervalos de atenção plena. Isso pode ser metaforicamente comparado com gotas de chuva escorrendo em uma janela que sempre param brevemente, enchem-se com água e, finalmente, continuam a fluir.

Isso levanta a questão sobre em que medida exatamente essa combinação de habilidades é aquilo que é treinado pela prática do Contato Improvisação: por um lado, poder se entregar total e completamente a uma atividade, e, por outro lado, simultaneamente manter uma atenção plena para poder se distanciar, quando for o caso, de ações impulsivas, no intuito de poder perceber possibilidades alternativas de ação.

\section{Referências $^{37}$}

Frost, K. (1999). Some Short Stories about Sex and Contact. Contact Quarterly, 24, I. In Source book II. Collected writings and graphics from Contact Quarterly dance journal 1993-2007. Contact Editions, MA,188.

Hassmann, J. (2006). Thoughts about CI. Unveröffentlichtes Skript.

Heitkamp, D. (2007). Sexualität und Kontaktimprovisation. In Tanzjournal 4/2007, Friedrich Berlin Verlag, Berlin. Zitiert aus URL: http://www.contact-improvisation. net/develop/wiki/index.php/Sexualit\%C3\%A4t_und_Kontaktimprovisation, Zugriff am12.7.09.

Kirschner, W. (2000). Aspekte des Leiberlebens in der Kontaktimprovisation. Zeitschrift für Musik-, Kunst- und Tanztherapie, (2), 65-79.

Kirschner, W. (2004). Prinzipien "berührender" Entspannungsarbeit. Praxis der Psychomotorik, 2 (29), 114-119.

Lori, B. (1994). Sex Talk. Contact Quarterly, 19, 2. Zitiert aus Source book II. Collected writings and graphics from Contact Quarterly dance journal, 1993-2007. Contact Editions, MA, 38-40.

\footnotetext{
${ }^{37}$ [Trago aqui somente parte das referências bibliográficas da Tese de Doutorado de Schmid - somente aquilo que ele citou nessa parte traduzida.]
} 
Novack, C. J. (1990). Sharing the dance. Madison, Wis.: Univ. of Wisconsin Press.

Pallant, C. (2006). Contact improvisation. Jefferson, NC: McFarland.

Paxton, S. (1976). Contact Quarterly, 3 (1)

Schmid, J. (2009a). Kontakt-Improvisation und Flow-Erleben. In: T. Kaltenbrunner (Hrsg.): Contact Improvisation. Aachen: Meyer und Meyer, 215-221.

\section{Sites da Internet}

- URL:http://www.contactfestival.de/archiv/past.htm.

- URL: http://www.contactencyclopedia.net

- URL: http://www.ECITE.org;

- URL: http://groups.yahoo.com/group/ECITE-forum

- URL: www.Oster-improvfestival.org

Recebido em: 18/09/2017 Aprovado em: 18/09/2917 